\title{
SULFATOS SECUNDÁRIOS DE ITAQUAQUECETUBA, ESTADO DE SÃO PAULO
}

\author{
Daniel ATENCIO \\ Raphael HYPOLITO
}

\begin{abstract}
RESUMO
Os sulfetos de ferro pirita e marcassita ocorrem como cimento em rochas sedimentares da Formação Itaquaquecetuba, no município homônimo, Estado de São Paulo. A exposição destes minerais a condições oxidantes provoca a formação de soluções ácidas de sulfato de ferro que atacam feldspatos, micas e outros minerais, enriquecendo-se em potássio, sódio, cálcio, alumínio e magnésio. A partir dessas soluções precipitam sulfatos contendo esses cátions. Estudos mineralógicos permitiram a identificação dos sulfatos melanterita, rozenita, coquimbita, metavoltina, alunogênio, epsomita e gipsita, bem como minerais dos grupos da halotriquita, copiapita e alunita. Várias transformações mineralógicas ocorreram após a coleta das amostras, incluindo a formação de materiais não observados nos afloramentos de Itaquaquecetuba, como römerita, paracoquimbita e um sulfato de ferro amorfo. O hábito de minerais e agregados - crostas, agregados sacaroidais ou fibrosos e estalactites - reflete cristalização rápida. A sequência de formação dos sulfatos de Itaquaquecetuba é a seguinte: 1) sulfatos hidratados de ferro (II);2) sulfatos hidratados de ferro (II), ferro (III) e outros cátions; 3) hidroxissulfatos hidratados de ferro (III) e outros cátions. Após esta etapa, duas linhagens divergentes são aparentes, uma com a formação de sulfatos hidratados de ferro (III) e outra com a formação de hidroxissulfatos de ferro (III), eventualmente com outros cátions. A etapa final da alteração produz goethita.
\end{abstract}

Palavras-chave: sulfatos secundários, intemperismo, Formação Itaquaquecetuba, São Paulo.

\section{ABSTRACT}

Iron sulfides, pyrite and marcasite, occur as cement in the Itaquaquecetuba Formation rocks. Exposure of these minerals to oxidizing conditions causes the formation of acid solutions, which attack feldspars, micas and other materials. Iron, aluminum, calcium, magnesium, potassium, and sodium sulfates precipitate from these solutions. Mineralogical and chemical studies allowed the identification of sulfates melanterite, rozenite, coquimbite, metavoltine, alunogen, epsomite, and gypsum, as well as minerals of the halotrichite, copiapite and alunite groups. Several mineralogical transformations took place after sample collection, including the formation of materials not observed in the Itaquaquecetuba outcrops, such as römerite, paracoquimbite, and an amorphous iron sulfate. The habit of the minerals and aggregates - crusts, saccharoidal or fibrous aggregates and stalactites - reflects rapid crystallization. The approximate sequence of formation of the Itaquaquecetuba sulfates is: 1) hydrated iron (II) sulfates; 2) hydrated sulfates of iron (II), iron (III) and other cations; 3 ) hydrated hydroxysulfates of iron (III) and other cations. After this stage, two divergent lineages are apparent, one with the formation of hydrated iron (III) sulfates and the other with the formation of hydroxysulfates of iron (III) and possibly other cations. The final stage of alteration produces goethite.

Keywords: secondary sulfates, weathering, Itaquaquecetuba Formation, São Paulo. 


\section{INTRODUÇÃO}

Os sulfetos de ferro pirita e marcassita ocorrem como cimento nas rochas sedimentares da Formação Itaquaquecetuba, Bacia de São Paulo (COIMBRA et al. 1983). A abertura de cavas para extração de areia coloca estes minerais em contato com ambiente oxidante, o que os torna instáveis. Soluções fortemente ácidas, com valores de $\mathrm{pH}$ entre 2,30 e 2,90, são geradas pela alteração dos sulfetos, e instabilizam, inclusive, feldspatos e filossilicatos. A partir dessas soluções, precipitam sulfatos de ferro, alumínio, cálcio, magnésio, potássio e sódio, além de goethita (ATENCIO 1986).

É importante salientar que os sulfatos formados sobre as rochas da Formação Itaquaquecetuba são, em geral, facilmente solúveis em água e, consequentemente, seus íons podem ser incorporados às águas subterrâneas. $\mathrm{O}$ consumo de águas ricas em sulfato, como aquelas coletadas em poços de argila do nordeste brasileiro, provoca sérios problemas de saúde aos seres humanos e animais. Neste contexto, ZODROW \& McCANDLISH (1978) realizaram estudos em Nova Scotia, Canadá, buscando identificar poluentes de água associados à oxidação de sulfetos. Com o mesmo objetivo, MACHADO \& LIMA (1984) investigaram os efeitos em águas superficiais e subterrâneas provocados pela mineração de carvão rico em sulfetos na área de Siderópolis, Santa Catarina, Brasil. Novas investigações sobre o tema podem ser encontradas em FRAU (2011).

Neste trabalho o enfoque principal é a caracterização mineralógica dos sulfatos formados sobre as rochas da Formação Itaquaquecetuba. A partir desses resultados, e balizado por resultados de análises químicas dos minerais (ATENCIO 1986), é sugerida uma sequência de formação dos sulfatos.

\section{GEOLOGIA, LOCALIZAÇÃO E ACESSO}

Os depósitos terciários da Bacia de São Paulo, que abrangem sedimentos das formações São Paulo e Itaquaquecetuba, têm sido interpretados como um conjunto sedimentar paleógeno, composto por um sistema de leques aluviais e canais entrelaçados em sua base, um sistema lacustre (em parte sincrônico com o anterior) e um sistema fluvial meandrante no topo. A interpretação da Formação Itaquaquecetuba (sistema fluvial entrelaçado) é controvertida, sendo ora considerada como pertencente aos depósitos basais, ora como produto de reativação tectônica e retrabalhamento de sedimentos no Neógeno ou mesmo Quaternário (LIMA et al. 1991). As melho- res exposições dessa unidade, alvo dessa pesquisa, estão nos portos de areia (Figura 1) localizados na cidade de Itaquaquecetuba, nas vizinhanças dos municípios de Poá e Suzano, cerca de $40 \mathrm{~km}$ a leste do centro da cidade de São Paulo. O principal acesso à área é feito pela Rodovia Ayrton Senna.

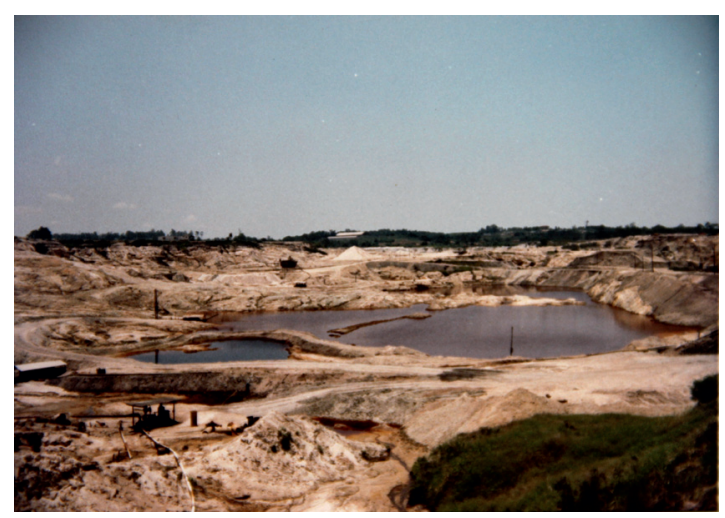

FIGURA 1 - Vista parcial de porto de areia em Itaquaquecetuba.

\section{MATERIAIS E MÉTODOS}

Várias visitas às cavas dos portos de areia de Itaquaquecetuba permitiram a descrição dos minerais em campo e a coleta de amostras. Após sua coleta e armazenamento, diversas transformações mineralógicas puderam ser observadas em laboratório em condições ambientais. Todas as amostras foram caracterizadas petrográfica, mineralógica e texturalmente nos laboratórios do Instituto de Geociências da USP e do Instituto de Pesquisas Tecnológicas do Estado de São Paulo (IPT). As técnicas da difração de raios $\mathrm{X}$ foram aplicadas para análises qualitativas, sobretudo para a classificação dos sulfatos em grupos isoestruturais, utilizando um difratômetro da marca Rigaku, modelo Geigerflex D/ Max. As análises químicas dos sulfatos, bem como o estudo das águas e outros materiais associados, foram detalhados nos trabalhos de ATENCIO (1986) e ATENCIO \& HYPOLITO (1988).

\section{SULFATOS DE ITAQUAQUECETUBA}

Com base na metodologia descrita anteriormente, foram identificados os sulfatos listados a seguir.

- Melanterita $-\mathrm{Fe}^{2+} \mathrm{SO}_{4} \cdot 7 \mathrm{H}_{2} \mathrm{O}$, monoclínico.

Melanterita ocorre como agregados pulverulentos ou com textura sacaroidal, de cor branca ou 
esverdeada, algumas vezes ligeiramente azulada, em íntima associação com diversos outros sulfatos (minerais dos grupos da halotriquita e alunita, rozenita, alunogênio e gipsita). Eventualmente possui cor branca amarelada, devido à presença de minerais do grupo da copiapita e metavoltina ( $\mathrm{Fi}$ gura 2).

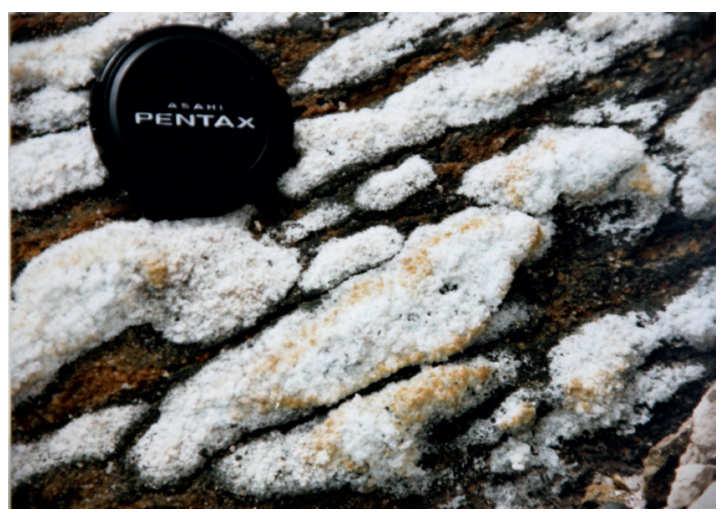

FIGURA 2 - Melanterita, mineral do grupo da halotriquita, rozenita e gipsita - indistinguíveis macroscopicamente - sobre sulfetos coletados em plano de falha. A cor amarela é devida a mineral do grupo da copiapita e metavoltina.

Certos espécimes de melanterita verde-clara são recobertos por crosta botrioidal de coloração branca, constituída por um mineral do grupo da halotriquita e melanterita (Figura 3).

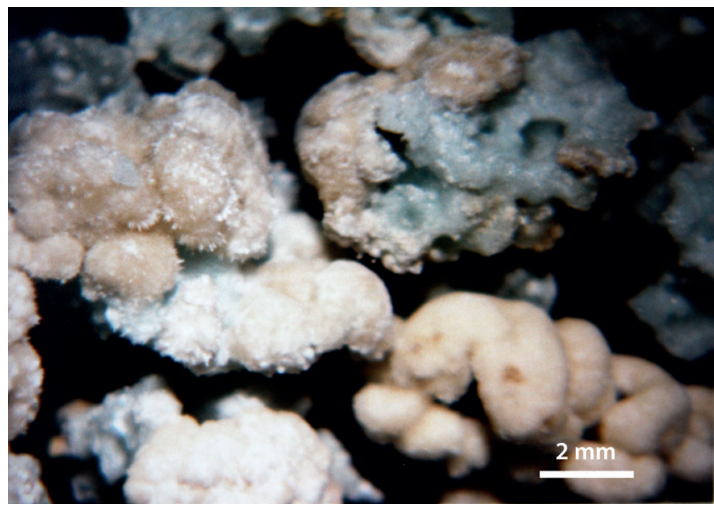

FIGURA 3 - A porção verde (canto superior direito) é constituída predominantemente por melanterita e a branca por mineral do grupo da halotriquita e melanterita.

Uma amostra de arenito cimentado por sulfetos, armazenada em laboratório, alterou-se parcialmente e deu origem a cristais encurvados de melanterita (Figura 4). A sequência do processo de alteração levou à formação de um mineral do grupo da copiapita e, posteriormente, de römerita.

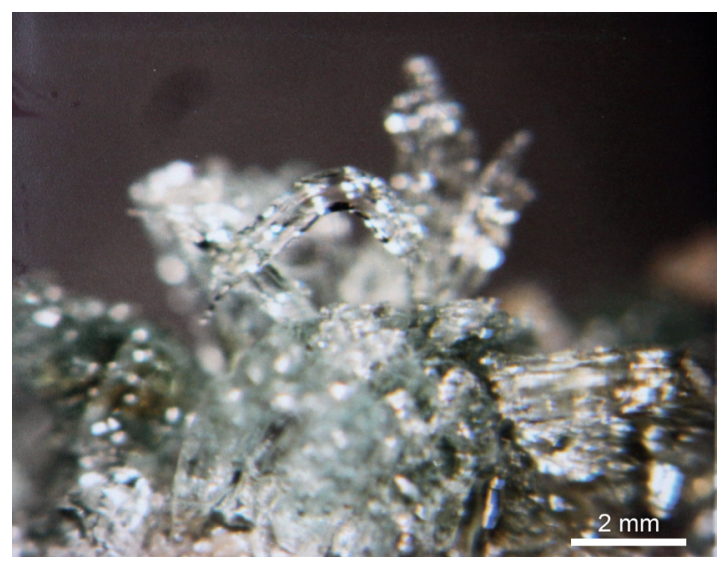

FIGURA 4 - Cristais encurvados de melanterita, formados por alteração de arenito cimentado por sulfeto, após a coleta e armazenagem da amostra em laboratório.

Com o passar do tempo, algumas amostras de melanterita verde-clara, quando mantidas em recipiente fechado, tiveram sua coloração modificada para laranja escuro. No entanto, novos difratogramas de raios $\mathrm{X}$ não apresentaram diferenças com aqueles obtidos anteriormente à alteração. Observou-se ao microscópio que os cristais de melanterita haviam sofrido dissolução parcial, apresentando inclusões líquidas e gasosas, além de estarem envolvidos por gel de coloração laranja. Essas inclusões, bifásicas ou trifásicas, apresentavam cristais ripiformes euedrais de gipsita, remanescentes da dissolução. Observou-se posteriormente que o material gelatinoso cristalizou-se na forma de agregados isolados com aspecto terroso, de coloração laranja, constituídos por mineral do grupo da copiapita. Com a transformação do gel nestes agregados, os cristais de melanterita voltaram a apresentar a coloração verde original. Os agregados de aspecto terroso adquiriram cor amarela após secagem.

- Rozenita $-\mathrm{Fe}^{2+} \mathrm{SO}_{4} \cdot 4 \mathrm{H}_{2} \mathrm{O}$, monoclínico.

Rozenita foi identificada em associação a melanterita e outros sulfatos em diversas amostras. 
Em um espécime, pôde-se constatar a formação de massas brancas de rozenita sobre melanterita verde, quando esta ficou exposta por alguns minutos sob o calor de uma lâmpada (Figuras 5 e 6).

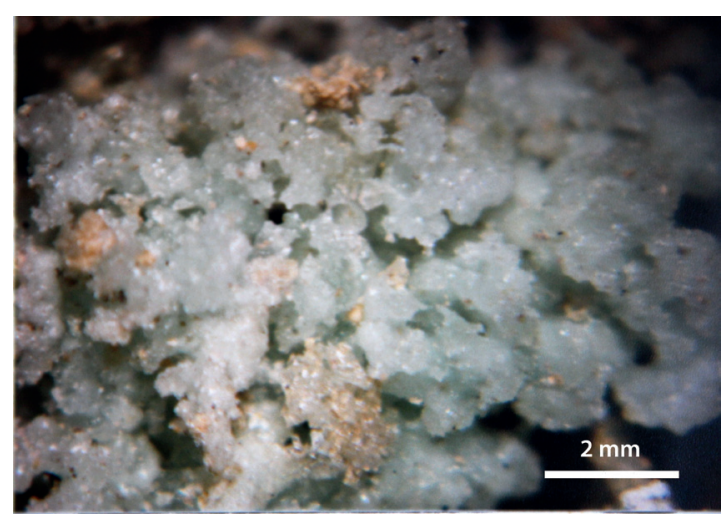

FIGURA 5- Cristais sacaróides de melanterita de coloração verde-clara.

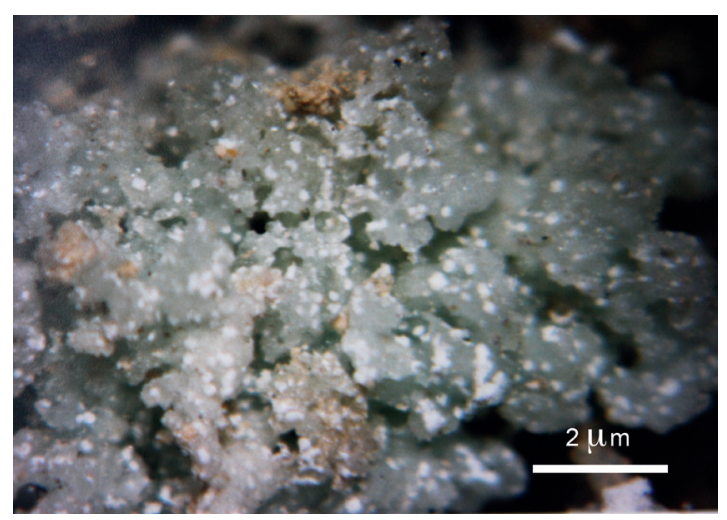

FIGURA 6 - Rozenita de coloração branca formada sobre os cristais de melanterita da figura anterior, fotografada alguns minutos depois.

- Grupo da halotriquita

$$
\begin{aligned}
& \text { - } \text { halotriquita }-\mathrm{Fe}^{2+} \mathrm{Al}_{2}\left(\mathrm{SO}_{4}\right)_{4} \cdot 22 \mathrm{H}_{2} \mathrm{O}, \\
& \text { monoclínico. } \\
& \text { - bilinita }-\mathrm{Fe}^{2+} \mathrm{Fe}^{3+}\left(\mathrm{SO}_{4}\right)_{4} \cdot 22 \mathrm{H}_{2} \mathrm{O}, \\
& \quad \text { monoclínico. } \\
& \text { - pickeringita }-\mathrm{MgAl}_{2}\left(\mathrm{SO}_{4}\right)_{4} \cdot 22 \mathrm{H}_{2} \mathrm{O}, \\
& \quad \text { monoclínico. }
\end{aligned}
$$

Os minerais do grupo da halotriquita (comumente halotriquita ou bilinita, mais raramente pickeringita) apresentam-se como cristais aciculares, formando agregados pulverulentos, fibrorradiados ou botrioidais, nas cores branca, verde-clara ou rosada (Figuras 7 a 11).

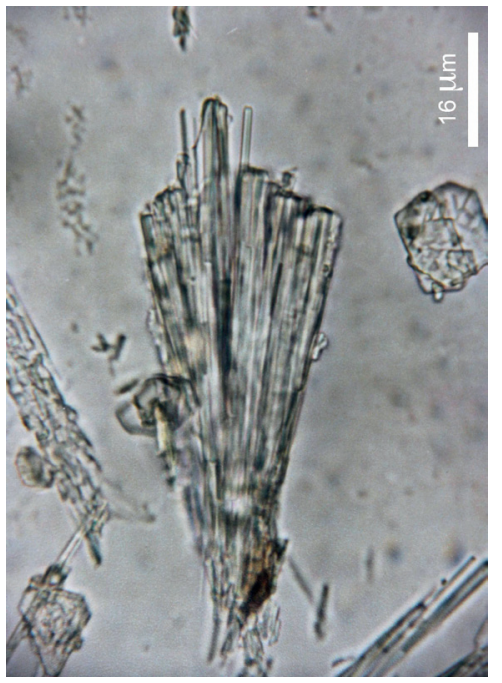

FIGURA 7 - Agregado de cristais aciculares, radiais e divergentes, de mineral do grupo da halotriquita. No alto, à direita, observa-se hexágono de metavoltina. Fotografia obtida em microscópio petrográfico com luz transmitida, polarizadores paralelos.

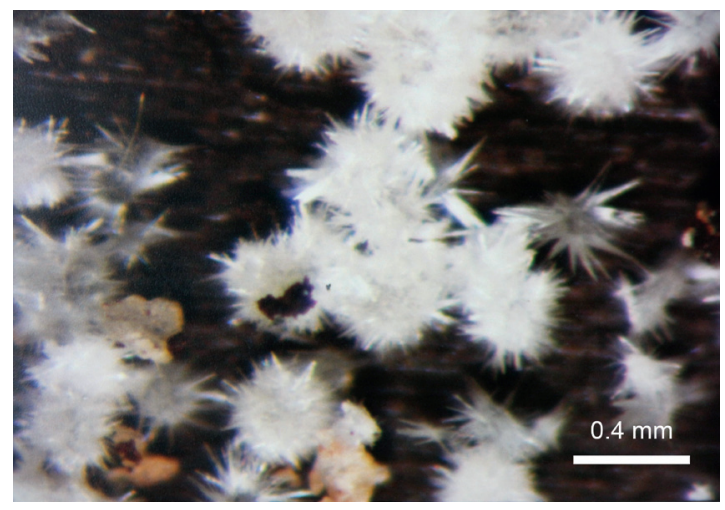

FIGURA 8 - Agregados fibrorradiados de mineral do grupo de halotriquita sobre madeira carbonificada.

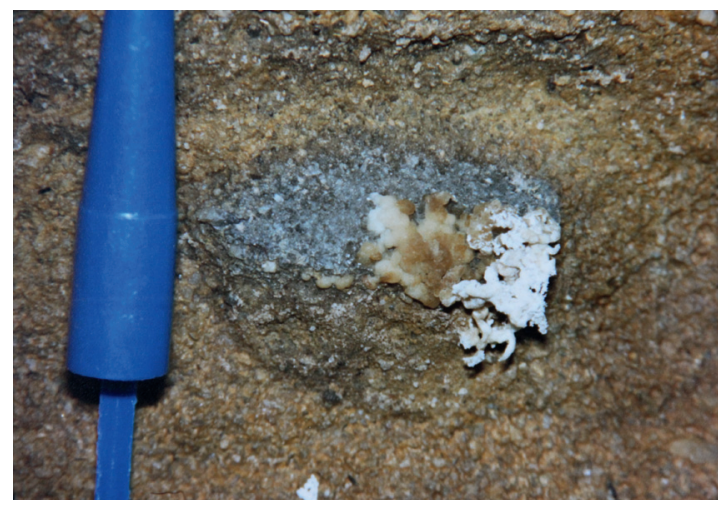

FIGURA 9 - Mineral do grupo da halotriquita, com coloração variando de branca a amarelada, formado sobre sulfetos. 


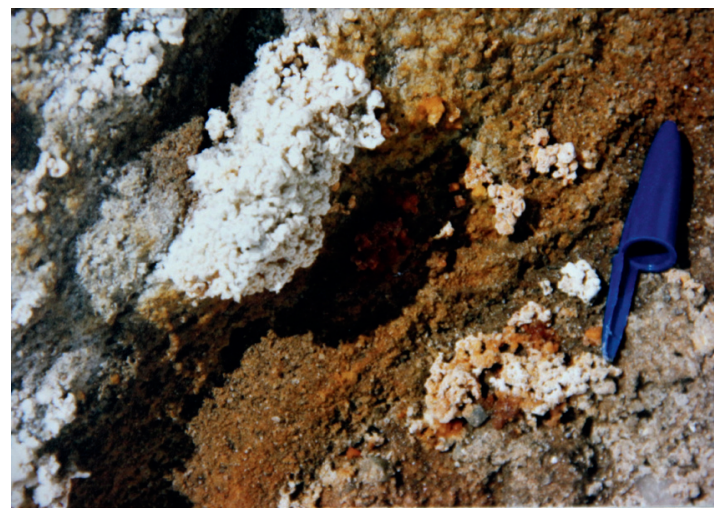

FIGURA 10 - Mineral do grupo da halotriquita, com coloração variando de branco a alaranjado escuro.

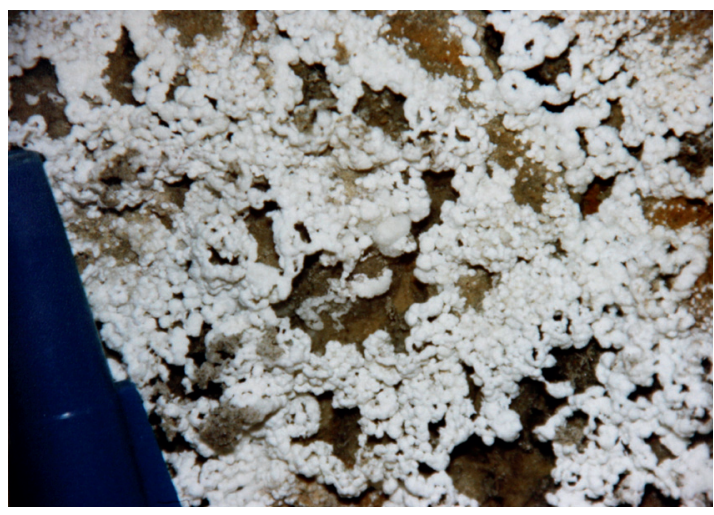

FIGURA 11 - Pickeringita, epsomita e alunogênio, indistinguíveis macroscopicamente.

Em blocos de rocha argilosa expostos na cava de mineração foram identificadas crostas branco-acastanhadas, de hábito vermiforme, constituídas por um mineral do grupo da halotriquita, melanterita e alunogênio (Figura 12).

Observou-se também a formação de feixes de cristais fibrosos com brilho sedoso, de até $6 \mathrm{~mm}$ de comprimento, de um mineral do grupo da halotriquita, sobre amostras de sulfetos armazenadas em frasco de vidro.

- Römerita $-\mathrm{Fe}^{2+} \mathrm{Fe}_{2}^{3+}\left(\mathrm{SO}_{4}\right)_{4} \cdot 14 \mathrm{H}_{2} \mathrm{O}$, triclínico.

Nas amostras de Itaquaquecetuba a römerita só se forma a partir da alteração dos sulfetos durante curto período de armazenamento das amostras em laboratório. Apresenta-se como agregados terrosos esféricos ou irregulares de coloração rosa-acastanhada, associada a gipsita e minerais do grupo da halotriquita. Sob a lupa, observa-se que os cristais são transparentes, de brilho vítreo e coloração rosa-clara; suas formas cristalinas também foram reconhecidas ao microscópio eletrônico de varredura (Figura 13).

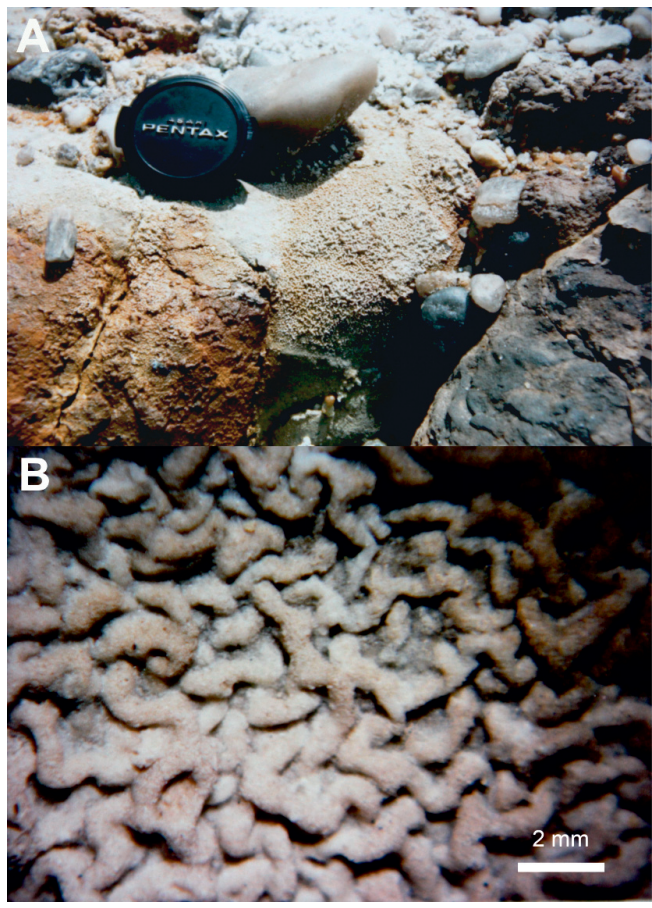

FIGURA 12 -A) Crostas vermiformes de mineral do grupo da halotriquita, melanterita e alunogênio. B) Detalhe da fotografia anterior.

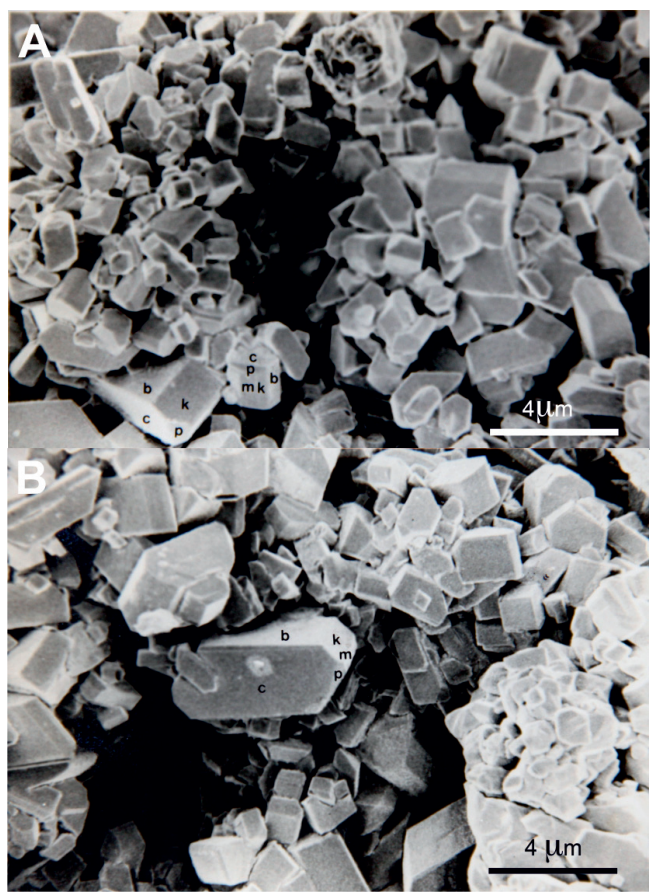

FIGURA 13 -A) Cristais de römerita observados em microscópio eletrônico de varredura (SEM), destacando-se as formas: b $\{010\}, \mathrm{c}\{001\}, \mathrm{k}$ $\{120\} . \mathrm{m}\{110\}$, e $\mathrm{p}\{111\}$. B) Observar cristal de hábito pseudo-cúbico (cuboidal), típico da römerita, no canto superior direito. 
- Coquimbita e paracoquimbita - ambos $\mathrm{Fe}_{2}^{3+}\left(\mathrm{SO}_{4}\right)_{3} \cdot 9 \mathrm{H}_{2} \mathrm{O}$, trigonal.

Coquimbita forma normalmente crostas de alteração de coloração branca, ligeiramente acastanhada ou rosada, sobre minerais do grupo da copiapita. Várias amostras de minerais do grupo da copiapita apresentaram apenas pequenos focos de alteração para coquimbita. No entanto, após um período de armazenagem no laboratório, verificou-se a transformação quase total para este mineral (Figura 14). A coquimbita associa-se também a minerais do grupo da halotriquita.

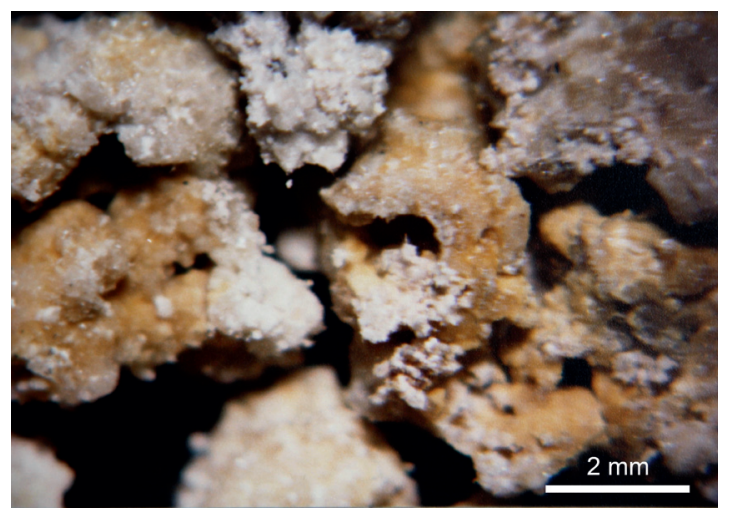

FIGURA 14 - Aluminocopiapita (coloração amarela) alterada parcialmente para coquimbita (coloração branca).

Um único registro de paracoquimbita foi efetuado. Macroscopicamente não foi possível distingui-la da coquimbita, com a qual se associa como produto de alteração de aluminocopiapita, após armazenagem em laboratório.

- Grupo da copiapita

- aluminocopiapita -

$\mathrm{Al}_{2 / 3} \mathrm{Fe}^{3+}{ }_{4}\left(\mathrm{SO}_{4}\right)_{6}(\mathrm{OH})_{2} \cdot 20 \mathrm{H}_{2} \mathrm{O}$, triclínico.

- ferricopiapita -

$\mathrm{Fe}^{3+}{ }_{2 / 3} \mathrm{Fe}^{3+}{ }_{4}\left(\mathrm{SO}_{4}\right)_{6}(\mathrm{OH})_{2} \cdot 20 \mathrm{H}_{2} \mathrm{O}$, triclínico.

- magnesiocopiapita -

$\mathrm{MgFe}_{4}^{3+}\left(\mathrm{SO}_{4}\right)_{6}(\mathrm{OH})_{2} \cdot 20 \mathrm{H}_{2} \mathrm{O}$, triclínico.

Os minerais do grupo da copiapita (comumente aluminocopiapita ou ferricopiapita) mostram-se como esferas isoladas de coloração amarela ou alaranjada (Figura 15). Cristais placóides euedrais pleocróicos, incolores a levemente amarelados, límpidos, com aproximadamente $20 \mu \mathrm{m}$, podem ser observados na figura 16. Crostas botrioidais de coloração amarela ou laranja, associadas a alunogênio e minerais do grupo da alunita, também são comuns (Figuras 17 e 18). Raramente, forma-se magnesiocopiapita (Figura 19).

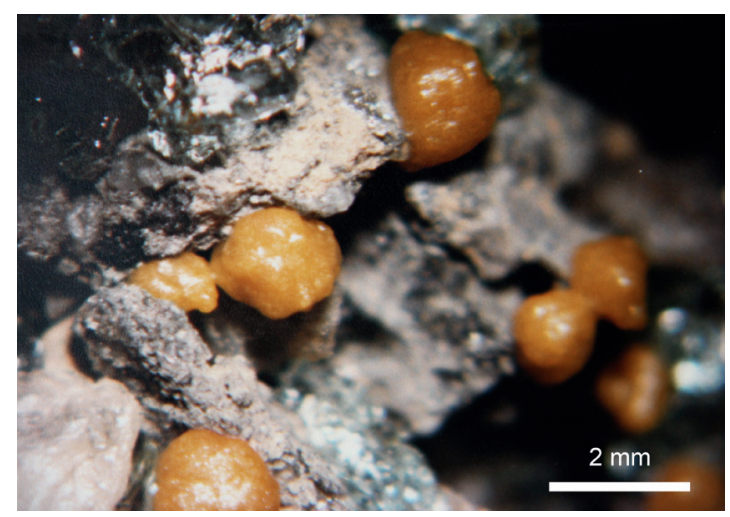

FIGURA 15 - Esferas de mineral do grupo da copiapita (coloração amarela-laranja), melanterita (verde ligeiramente azulado), sulfetos (cinza) e quartzo (branco).

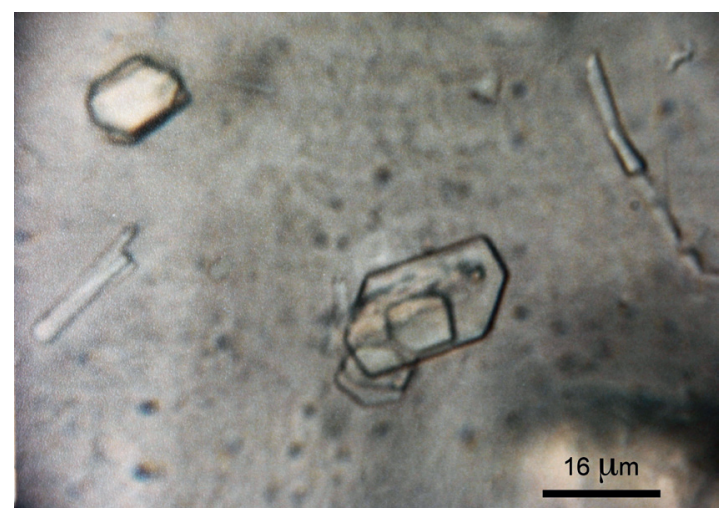

FIGURA 16 - Cristais placóides euedrais de mineral do grupo da copiapita, vistos em microscópio petrográfico com luz transmitida, polarizadores paralelos.

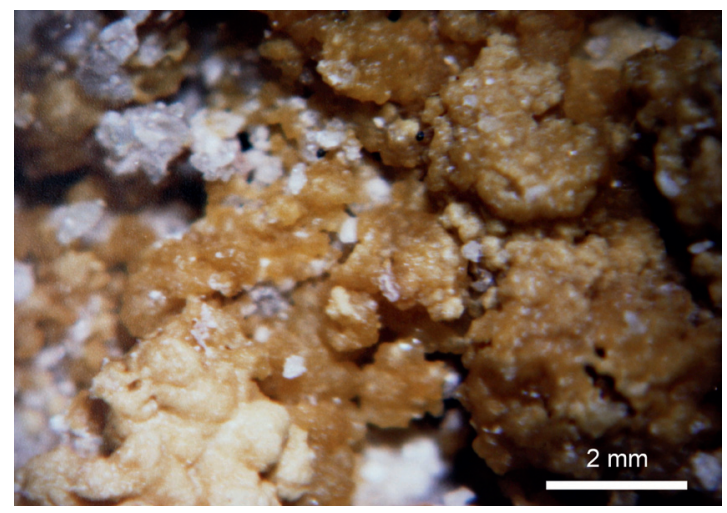

FIGURA 17 - Mineral do grupo da copiapita, em diversas tonalidades de amarelo. 


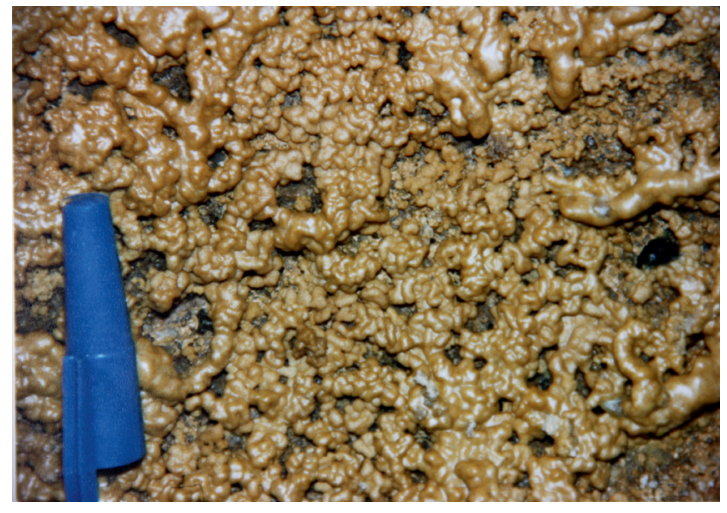

FIGURA 18 - Mineral do grupo da copiapita em agregados botrioidais.

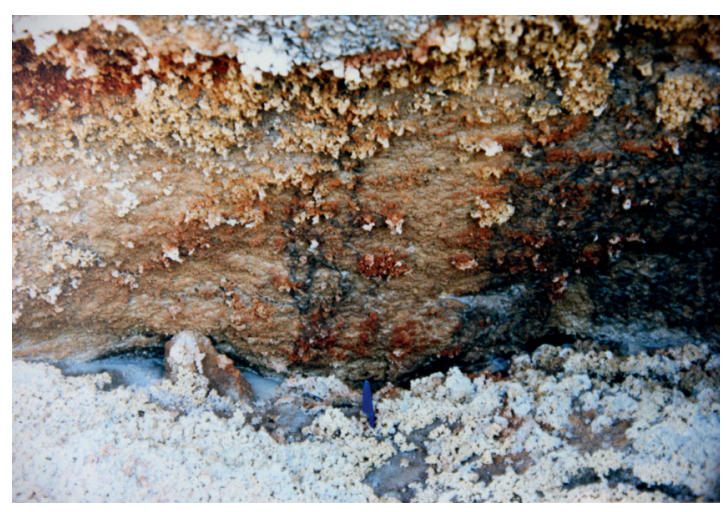

FIGURA 19 - Local de coleta das amostras de magnesiocopiapita, de coloração laranja, e de minerais do grupo da halotriquita.

A estabilidade dessas amostras em laboratório é diferenciada, uma vez que algumas se alteraram quase que totalmente e em poucos dias para material branco constituído de coquimbita e paracoquimbita, enquanto em outras amostras, esta alteração não foi observada ou se processou em pequena escala.

\section{- Grupo da alunita}

- hidroniojarosita - $\left(\mathrm{H}_{3} \mathrm{O}\right) \mathrm{Fe}^{3+}{ }_{3}\left(\mathrm{SO}_{4}\right)_{2}(\mathrm{OH})_{2}$, trigonal.

- natrojarosita $-\mathrm{NaFe}_{3}^{3+}\left(\mathrm{SO}_{4}\right)_{2}(\mathrm{OH})_{2}$, trigonal.

- jarosita $-\mathrm{KFe}_{3}^{3+}\left(\mathrm{SO}_{4}\right)_{2}(\mathrm{OH})_{2}$, trigonal.

Os minerais do grupo da alunita (comumente hidroniojarosita, raramente natrojarosita ou jarosita) formam crostas delgadas de coloração alaranjada em paredes de arenito, associados principalmente a alunogênio e, em menor proporção, a gipsita e minerais do grupo da copiapita (Figura
20). Algumas vezes minerais do grupo da alunita associam-se a goethita em estalactites de cor alaranjada a castanho (Figura 21A, B, C). Um corte transversal em uma estalactite (Figura 21D) permite visualizar anéis de coloração alaranjada, menos consistentes, alternados com outros de coloração castanha, de maior resistência, onde se concentra preferencialmente a goethita.

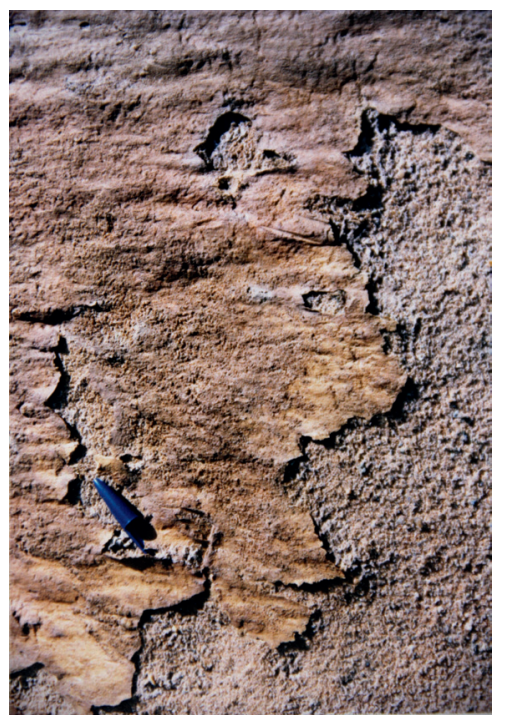

FIGURA 20 - Crosta delgada de hidroniojarosita em parede de arenito.

Os agregados de minerais do grupo da alunita sob a forma de espeleotemas apresentam estrutura porosa. Verifica-se o crescimento de musgo sobre as estalactites, por vezes, recoberto por gipsita (Figura 22). No plano horizontal, por onde migrou a solução que deu origem aos espeleotemas, há formação de hidroniojarosita com textura de fluxo.

Em laboratório, os processos de dissolução de crostas amarelas de minerais do grupo da copiapita e de separação de argilominerais levaram à concentração de minerais do grupo da alunita. Em campo, minerais do grupo da alunita ocorrem também associados a material argiloso de coloração amarela, muito úmido e inconsistente.

- Metavoltina $-\mathrm{K}_{2} \mathrm{Na}_{6} \mathrm{Fe}^{2+} \mathrm{Fe}^{3+}{ }_{6}\left(\mathrm{SO}_{4}\right)_{12} \mathrm{O}_{2} \cdot 18 \mathrm{H}_{2} \mathrm{O}$, trigonal.

Metavoltina, originada a partir de sulfetos, foi registrada apenas em uma amostra que preenche um plano de falha no embasamento gnáissico. Encontra-se associada a minerais dos grupos da halotriquita e copiapita, melanterita, rozenita e gipsita. 


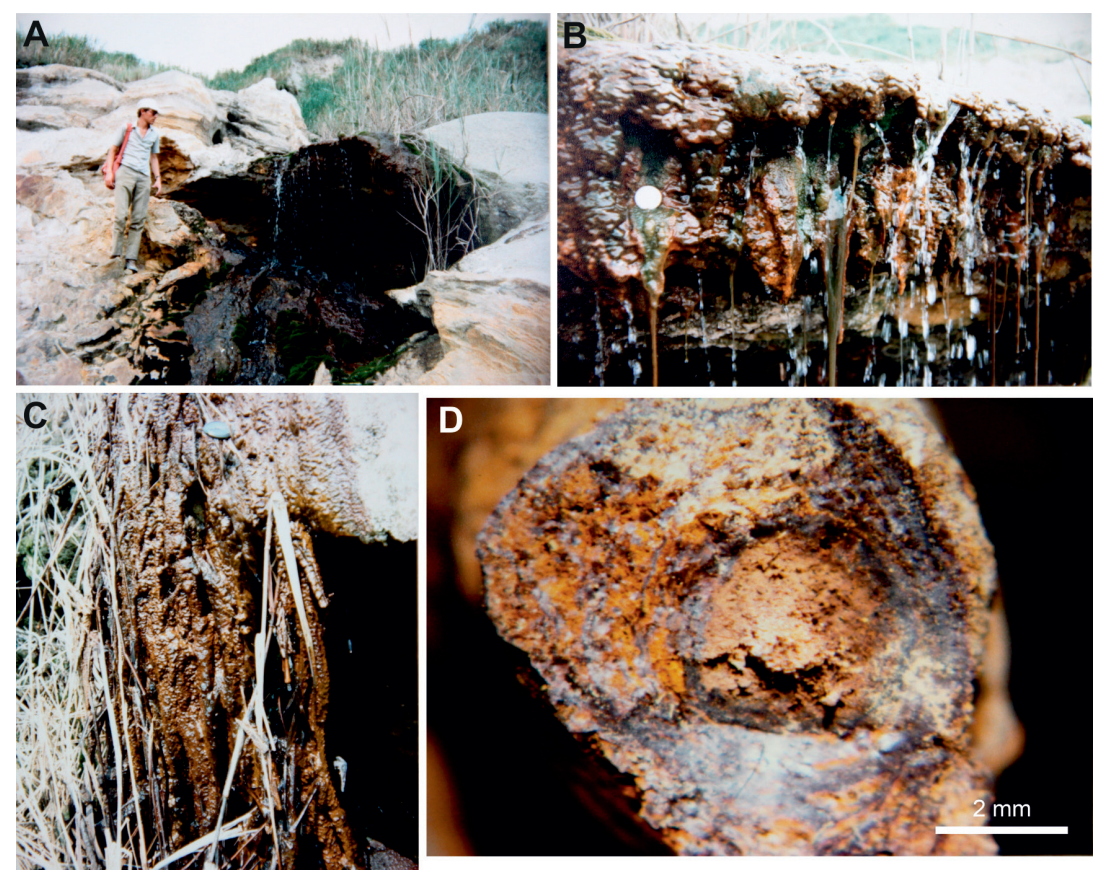

FIGURA 21 - A) Pequena cavidade onde foram coletadas amostras de estalactites de hidroniojarosita e goethita. B) Detalhe das estalactites que se formam a partir de fluxos aquosos e ao redor de capim (C). D) Corte transversal da estalactite, mostrando anéis escuros de goethita intercalados com anéis de coloração alaranjada de hidroniojarosita.

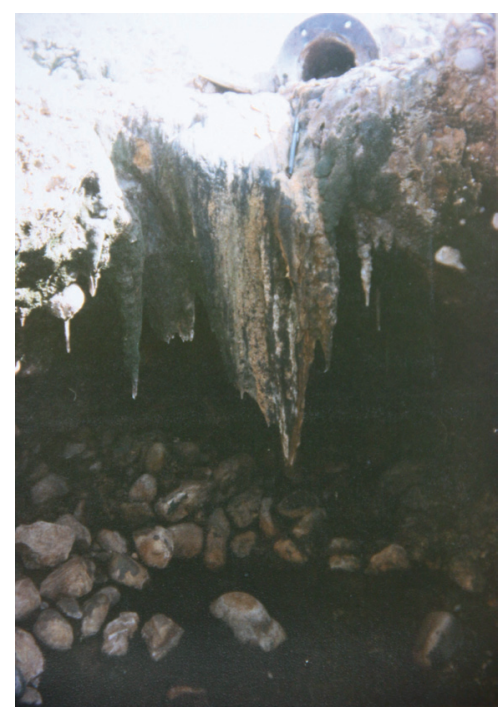

FIGURA 22 - Estalactites de hidroniojarosita e goethita, recobertas por musgo e gipsita.

Apresenta-se como cristais placóides euedrais de contorno hexagonal perfeito, coloração amarela-limão, límpidos e com dimensões variando de 10 a $20 \mu \mathrm{m}$. Às vezes, as placas empilham-se paralelamente formando agregados espessos (Figura 23). Cristais de mineral do grupo da copiapita, igualmen- te euedrais e de dimensões semelhantes, também são observados em associação à metavoltina.

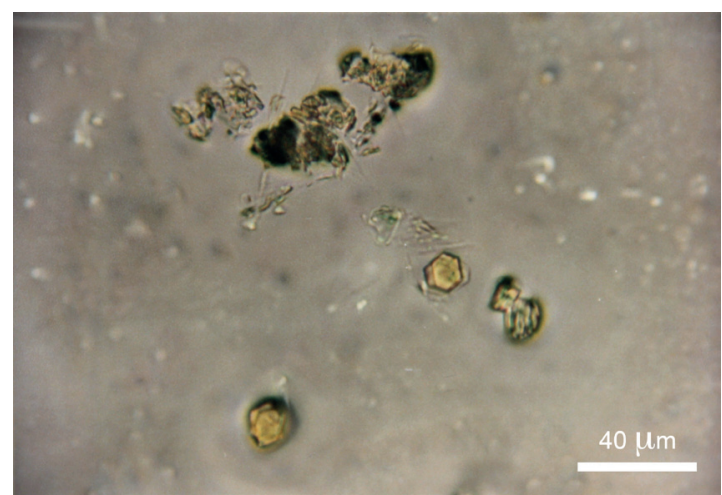

FIGURA 23 - Cristais de contorno hexagonal de metavoltina e agregados do mesmo mineral, cujos cristais apresentam-se com o eixo c visto horizontalmente. Fotografia obtida em microscópio petrográfico com luz transmitida, polarizadores paralelos.

- Alunogênio - $\mathrm{Al}_{2}\left(\mathrm{SO}_{4}\right)_{3} \cdot 17 \mathrm{H}_{2} \mathrm{O}$, triclínico.

Alunogênio, identificado por difratometria de raios $\mathrm{X}$, em associação a praticamente todos os demais minerais, é sempre um constituinte menor, como observado anteriormente. 
- Epsomita - $\mathrm{MgSO}_{4} \cdot 7 \mathrm{H}_{2} \mathrm{O}$, ortorrômbico.

Identificada por difratometria de raios $\mathrm{X}$, a epsomita associa-se a pickeringita.

- Gipsita - $\mathrm{CaSO}_{4} \cdot 2 \mathrm{H}_{2} \mathrm{O}$, monoclínico.

Analogamente ao observado para o alunogênio, a gipsita está presente em pequenas proporções em quase todas as amostras. Alguns exemplares, entretanto, mostram que esse mineral pode ocorrer isoladamente ou associado a minerais do grupo da alunita. Apresenta-se sob diferentes formas: crostas delgadas brancas, cristais macroscópicos encurvados, pequenas estalactites, cristais incolores transparentes, cristais ripiformes euedrais alongados e agregados arborescentes (Figuras 24 a 27).

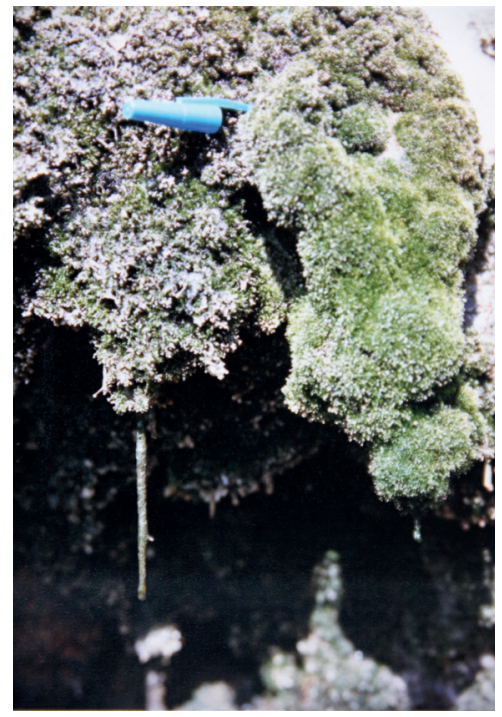

FIGURA 24 - Cristais de gipsita sobre musgo e pequenas estalactites.

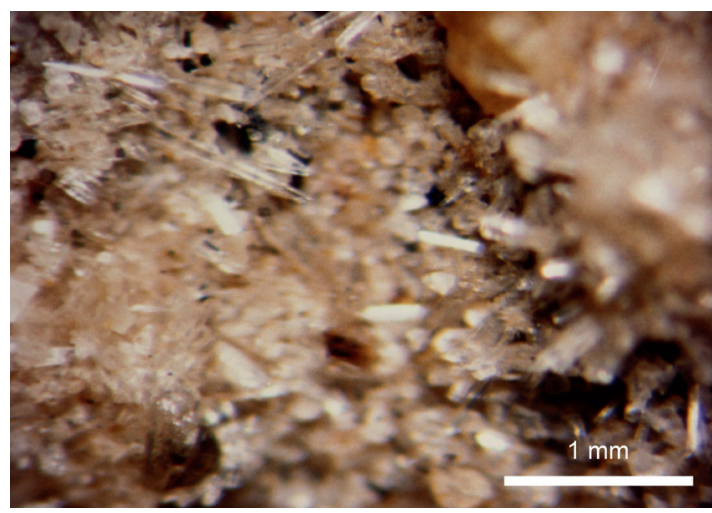

FIGURA 25 - Cristais alongados incolores e transparentes de gipsita.

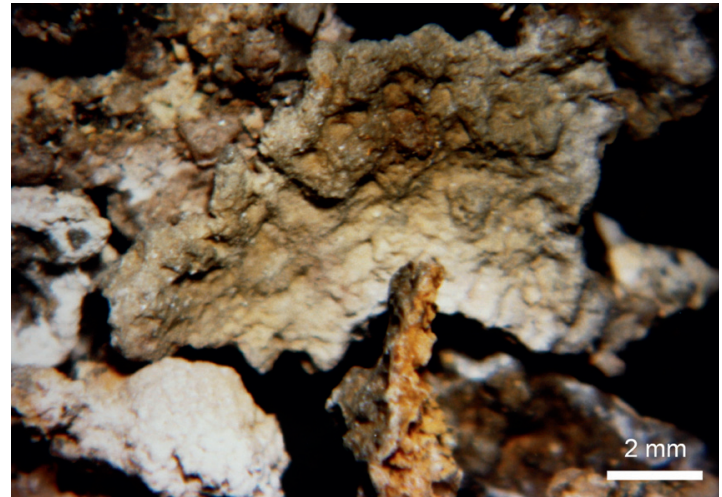

FIGURA 26 - Crosta delgada de gipsita. Na parte inferior da fotografia há um fragmento da crosta em perfil, onde se observa mineral do grupo da alunita (cor alaranjada) sob a gipsita.

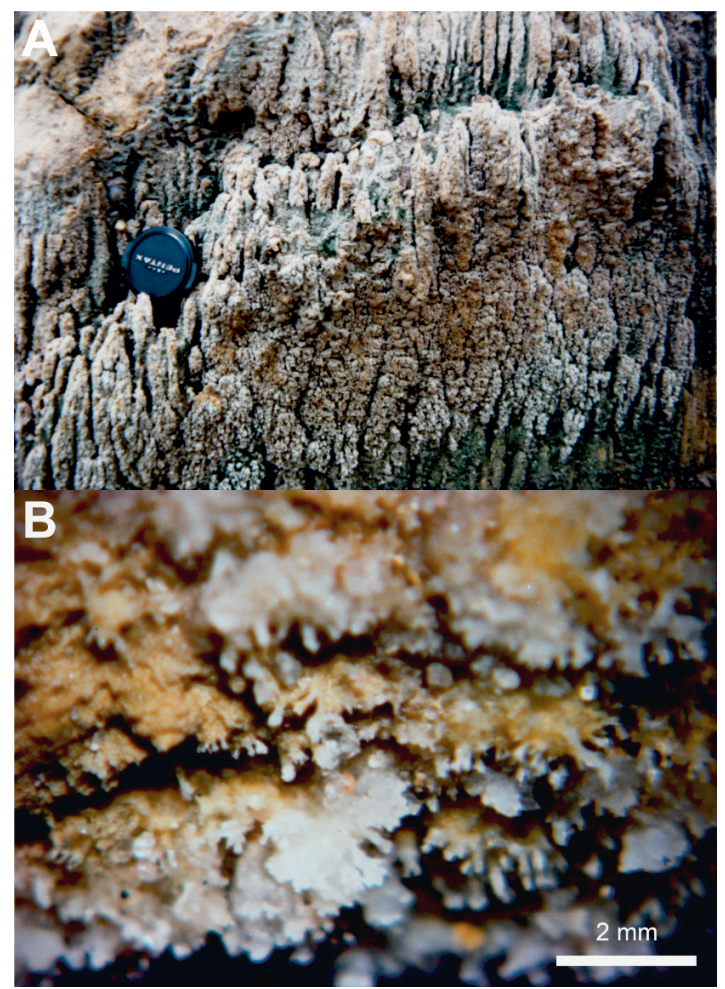

FIGURA 27 - A) Crosta de gipsita formada na superfície de um paredão vertical de arenito. B) Detalhe da fotografia anterior, ilustrando o hábito arborescente da gipsita e a associação com mineral do grupo da alunita (coloração alaranjada).

A gipsita pode ocorrer como um precipitado nas paredes verticais dos afloramentos, em cavidades, no piso da cava ou sobre musgo, seixos de quartzo e fragmentos recentes de madeira. 


\section{DISCUSSÃO DOS RESULTADOS}

Algumas interpretações genéticas e geoquímicas podem ser feitas a partir do estudo mineralógico e químico dos sulfatos formados sobre as rochas da Formação Itaquaquecetuba e dos produtos de transformação pós-coleta. O hábito, assim como a coloração, raramente podem ser utilizados para identificação dos sulfatos, quando observados individualmente. A associação de hábito e cor, entretanto, torna-se em alguns casos um critério diagnóstico. Os agregados sacaroidais de coloração verde-clara, por exemplo, são sempre de melanterita; as crostas botrioidais amarelas referem-se a minerais do grupo da copiapita, enquanto as crostas delgadas de coloração laranja a minerais do grupo da alunita. A cor rosa-acastanhada refere-se a römerita e consiste em um dos poucos exemplos onde a cor, isoladamente, permite a identificação de um mineral. No entanto, a cor branca, tingida por diversos matizes, relaciona-se a diversos minerais, como a melanterita, halotriquita e/ou bilinita, pickeringita, gipsita, rozenita e coquimbita, muitas vezes, apresentando hábitos idênticos. A coloração amarelada pode estar associada à impregnação de minerais do grupo da copiapita e metavoltina, ou a diferentes graus de hidratação, como no caso de minerais do grupo da halotriquita.

A coloração dos sulfatos estudados inclui várias tonalidades de verde, amarelo, branco, laranja, rosa e castanho. No entanto, tais variações não são função exclusiva do estado de oxidação do ferro, mas podem estar vinculadas às condições de cristalização, associação de fases amorfas e, principalmente, variações inter-relacionadas de temperatura e umidade relativa do ar.

O hábito dos minerais e agregados reflete, de modo geral, cristalização rápida, e consequentemente, a inibição do desenvolvimento de cristais bem formados. Os registros mais comuns referem-se a crostas botrioidais, maciças, vermiformes, pulverulentas ou arborescentes, massas sacaróides, agregados aciculares e fibrosos, estalactites e cristais encurvados. São raros os agregados onde o hábito acicular é visualizado a olho nu, tal como ocorre em algumas amostras de mineral do grupo da halotriquita.

Os processos de cristalização influem no desenvolvimento dos cristais e, consequentemente, em suas dimensões, transparência e coloração. Este efeito é notado, sobretudo, nas amostras de melanterita, que podem se apresentar na forma de massas cristalinas transparentes de coloração verde-clara ou agregados pulverulentos de coloração branca. A presença de um sulfato amorfo de ferro, por outro lado, pode transferir coloração alaranjada aos exemplares de melanterita.

A interdependência de cor e umidade relativa do ar nas amostras é especialmente nítida em crostas de minerais do grupo da copiapita, nas quais ocorre extensa gradação de tons de amarelo. O teor de água nos minerais deste grupo varia em função da temperatura e umidade atmosférica, sem que haja modificações estruturais. A coloração, no entanto, é bastante sensível a estas variações.

Algumas vezes, é difícil estabelecer se a variação da cor está associada aos teores de água ou à associação de fases amorfas, como no caso das amostras de coloração alaranjada dos minerais do grupo da halotriquita. A formação de mineral do grupo da copiapita nestas amostras, após o desaparecimento dessa cor, sugere o mesmo processo ocorrido em amostras de melanterita, ou seja, a formação de mineral a partir de material amorfo. A coloração alaranjada em amostras de magnesiocopiapita pode ter igual significado. $\mathrm{O}$ acréscimo de água na estrutura do mineral e a formação de produtos amorfos são provavelmente fenômenos relacionados. A água seria admitida na estrutura do mineral até o valor máximo, como no caso dos minerais do grupo da copiapita; o excesso de água passaria a atuar como um solvente ou condicionaria a geração de fases amorfas. Enquanto não é atingido o valor máximo, observa-se mudanças de coloração. Com o posterior decréscimo de umidade relativa do ar, as fases amorfas tendem a se recristalizar. No caso dos minerais do grupo da halotriquita e a melanterita, os teores de água na molécula variam dentro de intervalos menores.

O substrato exerce influência sobre os sulfatos precipitados e gera condições locais de $\mathrm{pH}$ e Eh favoráveis, ora à precipitação de um mineral, ora de outro. A melanterita encontra condições de cristalização sobre sulfetos e só raramente forma-se à distância destes. Já os minerais classificados como halotriquita e/ou bilinita formam-se sobre sulfetos (ou em sua proximidade), madeira carbonificada ou melanterita. A única amostra de pickeringita e epsomita identificada precipitou-se sobre embasamento gnáissico. Römerita forma-se sobre sulfetos e conserva fragmentos destes em sua massa. Dois tipos de coquimbita foram identificados: o primeiro, eventualmente associado a paracoquimbita, forma-se sobre minerais do grupo da copiapita, e o segundo, intimamente associado a mineral do grupo da halotriquita, ocorre sobre sulfetos. Minerais do grupo da alunita formam-se geralmente em superfí- 
cies expostas de arenito; sua ocorrência com melanterita sobre sulfetos é extremamente rara. Minerais do grupo da copiapita formam-se sobre arenitos e outras rochas silicáticas, mas eventualmente também sobre sulfetos, madeira carbonificada e outros sulfatos. Gipsita, por outro lado, forma-se sobre todos os materiais, apresentando condições favoráveis excepcionais de cristalização sobre musgo.

Em alguns casos, a presença de certos minerais nas amostras pode resultar de transporte mecânico e aprisionamento por outro material em formação. Um possível exemplo seriam os minerais do grupo da alunita em crostas de minerais do grupo da copiapita. Os minerais desse grupo são pouco solúveis e, assim, seus fragmentos podem ser transportados pelas águas superficiais juntamente com íons em solução. Com a precipitação destes íons, os fragmentos de minerais do grupo da alunita podem ser englobados pelo mineral neoformado.

Römerita, gipsita, coquímbita e minerais do grupo da alunita são bastante estáveis, assim como alguns minerais do grupo da copiapita. No entanto, vários sulfatos alteram-se rapidamente. $\mathrm{O}$ acompanhamento destes processos de alteração, aliado ao conhecimento do tipo de substrato de cada amostra, permite estabelecer considerações sobre a sequência de formação dos minerais.

Entre as transformações mineralógicas mais notáveis, ressalta-se a alteração de minerais do grupo da copiapita para os polimorfos coquimbita e paracoquimbita. $\mathrm{O}$ motivo para algumas amostras alterarem-se com maior facilidade do que outras não pôde ser elucidado. Porém, aparentemente, a associação com alunogênio ou altos teores de alumínio traria maior estabilidade aos minerais do grupo da copiapita.

$\mathrm{Na}$ sequência genética dos minerais foi possível observar a formação de melanterita a partir de sulfetos, seguida por mineral do grupo da copiapita e, posteriormente, römerita. Entretanto, tal sequência não representaria transformações sucessivas de um sulfato em outro, uma vez que todos podem se formar por alteração direta dos sulfetos, ainda que em períodos de tempo diferentes.

Observou-se a formação de produto amorfo a partir de melanterita, dando origem a mineral do grupo da copiapita. Com o acréscimo de temperatura, observou-se a desidratação da melanterita, com formação da rozenita. É provável que esta reação ocorra em sentido inverso, uma vez que as condições ambientais favorecem a estabilidade da melanterita.
ZODROW et al. (1979) comprovaram que a melanterita pode sofrer dois tipos de alteração: o primeiro tipo envolve perda de moléculas de água em um fenômeno de baixa energia, enquanto o segundo inclui fenômenos de maior energia, como a oxidação do ferro, formação de hidroxila e/ou oxônio e substituições por alumínio. Em Itaquaquecetuba, o primeiro fenômeno pode estar relacionado à formação de rozenita e o segundo, à formação de halotriquita e/ou bilinita, bem como minerais do grupo da copiapita. Em uma amostra, verificou-se uma crosta de mineral do grupo da halotriquita associado a melanterita (residual?) sobre melanterita, o que sugere a formação da halotriquita a partir da melanterita. Esta possível transformação, entretanto, não evoluiu durante o período de armazenagem da amostra.

Analisando a sequência genética, verifica-se, conforme o esperado, que os primeiros sulfatos a se formarem contêm apenas $\mathrm{Fe}^{2+}$; os seguintes são compostos de $\mathrm{Fe}^{2+}$ e $\mathrm{Fe}^{3+}$; e os últimos são constituídos unicamente por $\mathrm{Fe}^{3+}$. Comparando à sequência de formação estabelecida por BANDY (1938) e outros autores (hidrogenossulfatos $\rightarrow$ sulfatos $\rightarrow$ hidroxissulfatos de ferro), observa-se que: (1) nenhum hidrogenossulfato foi registrado em Itaquaquecetuba e (2) a formação de coquimbita e paracoquimbita (sulfatos sensu strictu) a partir de minerais do grupo da copiapita (hidroxissulfatos) contraria essa sequência. A introdução de outros óxidos no sistema $\mathrm{FeO}-\mathrm{Fe}_{2} \mathrm{O}_{3}-\mathrm{SO}_{3}-\mathrm{H}_{2} \mathrm{O}$ pode causar desvios na sequência, conforme sugerido por BANDY (1938). Estes desvios seriam motivados, provavelmente, por variações de $\mathrm{pH}$ e Eh. MERWIN \& POSNJAK (1937) estudaram uma sequência de alteração, onde a presença de vários íons influenciou a ponto de não se formarem hidrogenossulfatos, mas diferentes gerações de coquimbita, semelhante ao que foi verificado para os sulfatos de Itaquaquecetuba.

Com base nos dados mineralógicos e químicos dos sulfatos e materiais associados, pode-se sugerir a fonte dos íons contidos nos sulfatos. O enxofre é proveniente dos sulfetos pirita e marcassita. Calcopirita, identificada apenas nos gnaisses, contribui com quantidades ínfimas de enxofre. $\mathrm{O}$ ferro deriva dos sulfetos e, em menor proporção, da biotita. O alumínio é procedente de feldspatos e de seus produtos de alteração, além das micas. O cálcio está presente primariamente no plagioclásio. Uma parte do cálcio para formar a gipsita atual pode provir da gipsita singenética ou diagenética dos siltitos que ocorrem na Formação Itaquaquecetuba. O magnésio, assim como o manganês, deriva da biotita. O íon potássio é 
proveniente do microclínio, da biotita e da muscovita, enquanto o sódio provém do plagioclásio. Os sulfatos são geralmente pobres em potássio e sódio, devido a teores relativamente baixos destes íons nas rochas originais e à dificuldade em serem aceitos na estrutura da maioria dos minerais identificados em Itaquaquecetuba, nos quais não há posições catiônicas adequadas para íons monovalentes. Nesse sentido, o argumento utilizado por BROPHY \& SHERIDAN (1965), de que o baixo conteúdo em álcalis seria consequência da alteração mais rápida de sulfetos do que dos minerais associados, não se aplica ao presente caso, como comprovam os dados de soluções intempéricas naturais e de alteração simulada (ATENCIO \& HYPOLITO 1988).

Entre os cátions menores, o cobre, o níquel e o cobalto são oriundos principalmente de sulfetos, enquanto o zinco é originado de sulfetos e biotita. O lítio provavelmente é derivado de micas, onde substitui o alumínio e talvez o ferro e o magnésio em coordenação seis. É possível que isso também ocorra nos sulfatos, onde a proporção de lítio é, por vezes, superior à de potássio e sódio. $\mathrm{O}$ estrôncio substitui o cálcio e o potássio na biotita e nos feldspatos, enquanto o bário, não detectado em nenhum dos sulfatos, substitui o potássio na biotita e nos feldspatos. O chumbo, presente em quantidades reduzidas em algumas amostras de sulfatos e de rochas, provavelmente substitui o potássio em micas e feldspatos, além de possivelmente estar presente nos sulfetos.

Entre as rochas presentes em Itaquaquecetu$\mathrm{ba}$, o gnaisse contribui principalmente com biotita $\mathrm{e}$ plagioclásio, enquanto o pegmatito e o arenito fornecem microclínio e muscovita. Os argilominerais e produtos aluminossilicosos amorfos gerados pela alteração dos feldspatos armazenam diversos tipos de íons, que eventualmente são expulsos e se incorporam na estrutura de sulfatos. Os óxidos também abrigam grande variedade de íons procedentes da alteração dos minerais primários, diferindo, entretanto, pelo fato de serem estáveis, e, portanto, não contribuem com elementos para os sulfatos.

\section{CONSIDERAÇÕES FINAIS}

Estudos mineralógicos de amostras coletadas na Formação Itaquaquecetuba (Bacia de São Paulo) permitiram a identificação dos sulfatos melanterita, rozenita, römerita, coquimbita, paracoquimbita, metavoltina, alunogênio, epsomita e gipsita, bem como minerais dos grupos da halotriquita, copiapita e alunita.
Considerando-se os dados mineralógicos e químicos, pôde-se sugerir uma sequência de formação para os sulfatos de Itaquaquecetuba. A partir dos sulfetos, os primeiros sulfatos a se formarem seriam melanterita e rozenita. As condições locais de temperatura e umidade relativa do ar favorecem preferencialmente a cristalização de melanterita. A etapa seguinte corresponderia à formação de halotriquita e/ou bilinita. A römerita deveria fazer parte deste estágio de formação, mas, aparentemente, não encontra condições de cristalização no meio natural. Um dos tipos de coquimbita, associado a halotriquita e/ou bilinita, também deve fazer parte desse mesmo estágio. Amostras dessas etapas mostram resíduos de sulfeto em meio aos sulfatos. Os minerais do grupo da copiapita que formam crostas fora do contato com os sulfetos fariam parte de uma terceira etapa. Por outro lado, a formação de um mineral do grupo da copiapita, em intervalo de tempo posterior à formação de melanterita e anterior à de römerita em uma amostra, é coerente com os teores mais elevados de $\mathrm{Fe}^{2+}$. Assim sendo, existem gerações de minerais do grupo da copiapita com diferentes composições químicas, sugerindo que aquelas em contato com sulfetos conteriam maior proporção de $\mathrm{Fe}^{2+}$ que as mais distantes. Semelhanças nas dimensões, idiomorfismo e limpidez dos cristais levam a supor que o mineral metavoltina e o mineral associado do grupo da copiapita sejam, aparentemente, cogenéticos. Infere-se, portanto, que o mineral do grupo da copiapita contenha, analogamente ao que se observa para a metavoltina, o íon ferro nos dois estados de oxidação.

Após a terceira etapa de cristalização, referente à formação de minerais do grupo da copiapita com baixos teores de $\mathrm{Fe}^{2+}$, verifica-se uma separação em duas linhagens divergentes: uma com a formação de coquimbita e paracoquimbita, e outra com a formação de minerais do grupo da alunita. Goethita pode ser cogenética aos minerais do grupo da alunita ou formar-se em etapa posterior. Gipsita e alunogênio são encontrados em todas as associações estudadas, o que leva a crer que eles se formam desde os primeiros estágios. Quanto aos minerais pickeringita e epsomita, eventualmente cogenéticos, não foi possível estabelecer sua posição na presente sequência.

\section{REFERÊNCIAS BIBLIOGRÁFICAS}

ATENCIO, D. 1986. Sulfatos secundários: relação com rochas preexistentes e síntese. Instituto de Geociências, Universidade de São Paulo, Dissertação de Mestrado, 210 p. 
ATENCIO, D.; HYPOLITO, R. 1988. Soluções de intemperismo natural e simulado de sulfetos de Itaquaquecetuba, São Paulo. Anais da Academia Brasileira de Ciências, 60: 305-319.

BANDY, M.C. 1938. Mineralogy of three sulfate deposits of Northern Chile. American Mineralogist, 23: 669-760.

BROPHY, G.P.; SHERIDAN, M.F. 1965. Sulfate studies IV: The jarosite-natrojarositehydronium jarosite solid solution series. American Mineralogy, 50: 1595-1607.

COIMBRA, A.M.; RICCOMINI, C.; MELO, M.S. 1983. A Formação Itaquaquecetuba: evidências de tectonismo no Quaternário paulista. In: SBG, SIMPÓSIO REGIONAL DE GEOLOGIA, 4, São Paulo, Atas, 253-266.

FRAU, F. 2011.Acid production by $\mathrm{FeSO}_{4} \cdot n \mathrm{H}_{2} \mathrm{O}$ dissolution: Comment. American Mineralogist, 96:444-446.

LIMA, M.R.; MELO, M.S.; COIMBRA, A.M. 1991. Palinologia de sedimentos da bacia de São Pau- lo, Terciário do Estado de São Paulo, Brasil. Revista do Instituto Geológico, 12:7-20.

MACHADO, J.L.F. ;LIMA, J.E.S. 1984. Efeitos da mineração de carvão nos mananciais superficiais e subterrâneos na área de Siderópolis - SC. In: SBG, CONGRESSO BRASILEIRO DE GEOLOGIA, 33, Rio de Janeiro, Anais, 1: 284-294.

MERWIN, H.E.; POSNJAK, E. 1937.Sulphate incrustations in the Copper Queen Mine, Bisbee, Arizona. American Mineralogist, 22: 567-571.

ZODROW. E.L.; McCANDLISH, K. 1978. Hydrated sulfates in the Sidney coalfield, Cape Breton, Nova Scotia. Canadian Mineralogist, 16: 17-22.

ZODROW. E.L.; WILTSHIRE, J.; McCANDLISH, K. 1979. Hydrated sulfates in the Sidney coalfield, Cape Breton, Nova Scotia. II. Pyrite and its alteration products. Canadian Mineralogist, 17: 63-70.

Endereço dos autores:

Daniel Atencio e Raphael Hypolito - Instituto de Geociências, Universidade de São Paulo, Rua do Lago, 562, Cidade Universitária, CEP 05508-080, São Paulo, SP. E-mail: datencio@usp.br 